\title{
PERANCANGAN APLIKASI PERPUSTAKAAN BERBASIS DESKTOP DI SMP NEGERI 01 CITEUREUP
}

\author{
Revael Yos Panjaitan ${ }^{1}$, Helmi Veris Suparyo ${ }^{2}$, Lies Sunarmintyastuti ${ }^{3}$ \\ Program Studi Informatika, Fakultas Teknik dan Ilmu Komputer, Universitas Indraprasta PGRI \\ Jalan Raya Tengah No 80, Kelurahan Gedong, Pasar Rebo, Jakarta Timur \\ reyossy@gmail.com ${ }^{1}$, helmiveris78@gmail.com ${ }^{2}$, liesbina@yahoo.com ${ }^{3}$
}

\begin{abstract}
Abstrak
Tujuan penelitian ini untuk merancang aplikasi perpustakaan karena pada perpustakaan tersebut masih menggunakan buku catatan secara tertulis, sehingga ada buku yang belum terdata secara menyeluruh dengan baik oleh SMP Negeri 01 Citeureup. Pencarian buku yang dilakukan secara manual oleh siswa menyebabkan antrian dalam mencari buku menjadi lama, dalam memberikan denda terjadi kekeliruan soal berapa buku yang harus di denda. Serta proses pengolahan data-data buku yang ada di perpustakaan masih dilakukan secara manual. Dalam pembuatan laporan masih menggunakan pencatatan sehingga resiko kehilangan dan kerusakan buku terus terjadi. Dalam perancangan aplikasi yang ada pada SMP Negeri 01 Citeureup digunakan metode waterfall, aplikasi ini dibuat dengan menggunakan PHPMyAdmin untuk database dan aplikasi NetBeans sebagai alat bantu pembuatan aplikasi sistem informasi tersebut. Hasil dari penelitian adalah aplikasi ini dapat membantu proses pencatatan pendaftaran dan peminjaman buku, pengembalian buku dan membantu mempercepat proses pembuatan laporan dengan cepat.
\end{abstract}

Kata Kunci : Java, PHPMyAdmin, Aplikasi Perpustakaan, Netbeans, Sistem Informasi

\begin{abstract}
The purpose of this research is to design a library application, because the library still uses a notebook in writing. And then There is a book that is not well-datated thoroughly in the state Junior high School 01 Citeureup. Book searches that are done manually by students cause the queue in search of books to be long, in giving a fine error occurs on the book that must be in fines. As well as the process of logging the books that are in the library are still done manually. And the report creation still uses recording so that the risk of loss and damage to the book continues to occur. In the design of applications in the state Junior high School 01 Citeureup used waterfall method, this application is made by using PHPMyAdmin for database and NetBeans application as a tool for making such information system application. The result of the research is that the application can help the registration process, book lending, return books, and help the report quickly.
\end{abstract}

Keyword : Java, PHPMyAdmin, Library Application, Netbeans, Information system.

\section{PENDAHULUAN}

Ilmu pengetahuan dan teknologi selalu mengalami perkembangan secara dinamis, salah satu dari sekian banyak perkembangan teknologi adalah komputer. Komputer sebagai alat bantu manusia memiliki kelebihan diantaranya kecepatan, keakuratan, serta keefisienan dalam pengolahan data dibandingkan dengan sistem manual (Yakub, 2012). Dalam institusi pendidikan selalu membutuhkan sistem untuk mengumpulkan, mengelola, menyimpan, melihat kembali dan menyalurkan informasi. Komputer merupakan salah satu sarana yang dapat membantu kegiatan tersebut. Hasilnya sistem informasi berdasarkan komputer akan mempunyai nilai lebih dari pada sistem yang diolah secara konvensional, seperti pada suatu instansi pendidikan yang memiliki jumlah data cukup banyak maka perlu penanganan khusus (Subtari, 2012)

Memenuhi kebutuhan tersebut maka usaha yang dilakukan adalah membuat perancangan aplikasi perpustakaan yang dikhususkan bagi SMP Negeri 01 Citeureup. Bedasarkan interview dan observasi yang dilakukan, peneliti di SMP Negeri 01 Citeureup memliki guru-guru untuk menjalani tugasnya masing-masing dalam pengajaran kepada siswanya. Contohnya dalam perpustakaan SMP Negeri 01 Citeureup hanya memiliki 1 petugas perpustakaan. Peneliti menemukan permasalahanpermasalahan yang ada, yaitu belum adanya sistem terkomputerisasi khususnya di SMP Negeri 01 Citeureup, karena pada perpustakaan tersebut masih menggunakan buku catatan secara tertulis, kurangnya pemanfaatan teknologi yang ada dengan kata lain masih belum terkomputerisasi, masih ada buku yang belum terdata secara menyeluruh dengan baik oleh SMP Negeri 01 Citeureup, 
pencarian buku yang dilakukan secara manual oleh siswa sehingga terjadinya penumpukan antrian dalam mencari buku, dalam memberikan denda terjadi kekeliruan soal berapa buku yang harus di denda, dalam proses pengolahan data-data buku yang ada di perpustakaan, prosesnya masih dilakukan secara manual dimana, dalam pembuatan laporan masih menggunakan pencatatan sehingga rentan mengalami kehilangan dan kerusakan. Berdasarkan paparan yang telah diuraikan di atas, maka Judul yang diangkat untuk membahas masalah tersebut dalam penelitian ini adalah : "Perancangan Aplikasi Perpustakaan Berbasis Desktop Di SMP Negeri 01 Citeureup".

Adapun tujuan dari perancangan aplikasi perpustakaan berbasis desktop pendukung SMP Negeri 01 Citeureup adalah sebagai berikut untuk mengetahui perancangan aplikasi berjalan dengan baik, untuk mengetahui pengujian aplikasi di SMP Negeri 01 Citeureup, pendaftaran anggota perpustakaan menjadi lebih rapih dan terkomputerisasi dan laporan perpustakaan menjadi komputerisasi untuk menghindari kehilangan maupun kerusakan berkas.

Manfaat yang diharapkan dari penelitian ini agar memberikan manfaat untuk peneliti yaitu menambah pengetahuan dan wawasan baik teori maupun praktek melalui perancangan aplikasi perpustakaan dan memberikan kemudahan kepada petugas perpustakaan dalam proses penginputan buku, data anggota, data peminjaman buku, data pengembalian buku, penghitungan denda keterlambatan dalam pengembalian buku dan laporan dalam bentuk softcopy maupun tercetak.

\section{PENELITIAN RELEVAN}

Penelitian oleh (Syafriyanto, 2012) dengan judul Perancangan Sistem Informasi pada Perpustakaan SMK Hidayatut Thalibin Jakarta. Penelitian ini bertujuan untuk mengetahui sistem informasi perpustakaan yang sedang berjalan pada SMK Hidayatut Thalibin Jakarta, untuk merancang mengimplementasikan sistem informasi perpustakaan yang efektif dan efisien pada SMK Hidayatut Thalibin Jakarta. Hasil penelitian yang dilakukan dapat berjalan dengan baik dan mempermudah untuk pendataan dalam perpustakaan.

Penelitian oleh (Utapara, 2013) dengan judul Perancangan Sistem Informasi Perpustakaan Online pada SMP Sint Joseph Jakarta. Penelitian ini bertujuan untuk memproses sistem informasi secara online dalam mengelola pendaftaran, peminjaman, pengembalian, pembayaran denda dan memiliki sistem laporan yang ditunjukkan kepada kepala sarana dan prasarana SMP Sint Joseph Jakarta. Hasil penelitian yang dilakukan dapat berjalan dengan baik dan menyelesaikan permasalahan dalam pengelolaan yang ada dalam pendataan di perpustakaan.

\section{METODE PENELITIAN}

Metode Penelitian oleh cara ilmiah untuk mendapatkan data dengan tujuan dan kegunaan tertentu. Cara ilmiah didasarkan pada ciri-ciri keilmuan yaitu rasional, empiris, dan sistematis. Dalam melakukan suatu penelitian perlu dilakukan perencanaan penelitian agar penelitian yang dilakukan dapat berjalan dengan baik dan sistematis. Desain penelitian adalah semua proses yang diperlukan dalam perencanaan dan pelaksaan penelitian, dalam penelitian ini menggunakan jenis penelitian deskriptif dan penelitian tindakan (action research). Penelitian deskriptif yaitu penelitian yang menggambarkan secara sistematika dan akurat mengenai keadaan-keadaan nyata yang berjalan pada saat penelitian. Gambaran tersebut diperoleh dengan cara mengumpulkan, mengklasifikasikan, menyajikan, serta menganalisis data sehingga dapat ditarik suatu kesimpulan. Penelitian tindakan ialah penelitian yang bertujuan untuk mengembangkan keterampilanketerampilan baru, cara pendekatan baru, atau produk pengetahuan yang baru dan untuk memecahkan masalah dengan penerapan langsung di dunia aktual/lapangan. Peneliti memecahkan permasalahan yang ada dilapangan dengan mencari dan memilih alternatif metode pendekatan yang tepat.(Jogiyanto, 2012)

Penelitian dilakukan di SMP Negeri 01 Citeureup yang beralamat di Jl. Karanggan No. 33 Desa Puspasari Kecamatan Citeureup Kabupaten Bogor Provinsi Jawa Barat.

\section{Metode Pengumpulan Data}

Pengumpulan data secara lengkap yang berhubungan dengan penelitian ini dilakukan dengan cara survei. Data yang diperlukan adalah data primer dan data sekunder.

1. Sumber Data Primer 
Sumber data primer adalah biasanya data kualitatif yang diperoleh berdasarkan observasi dan wawancara (Haryanto, 2011). Data kualitatif adalah data yang tidak dihitung dengan hitungan bilangan, tetapi diukur dengan kata-kata bernilai, misalnya banyak, sedikit, kecil, rendah, manis, cantik, mahal, tinggi, panjang, berat dan sebagainya.

a. Metode Observasi (Observation Methods)

Teknik pengumpulan data dimana peneliti mengadakan pengamatan secara langsung terhadap gejala-gejala subjek yang diselidiki, baik pengamatan itu dilakukan didalam situasi yang sebenarnya maupun dilakukan didalam situasi buatan yang khusus diadakan pada masalah-masalah yang ada pada instansi terkait.

b. Wawancara (Interview)

Wawancara merupakan teknik pengumpulan data dengan melakukan tanya jawab secara lisan dengan orang-orang yang berhubungan dengan penelitian. Peneliti mengumpulkan data dan menggali informasi dengan mengajukan tanya jawab secara lisan dengan bagian petugas perpustakaan di SMP Negeri 01 Citeureup.

2. Sumber Data Sekunder

Sumber data sekunder adalah data yang digunakan untuk mendukung data primer (Haryanto, 2011). Jenis data primer merupakan jenis data yang sudah diolah terlebih dahulu oleh pihak pertama. Pengumpulan data yang dilakukan peneliti dengan cara membaca dan mempelajari buku-buku yang berhubungan dengan masalah yang diteliti untuk melengkapi dan menunjang data-data yang telah dipelajari dalam laporan.Data sekunder yang diperoleh dari instansi terkait seperti struktur organisasi, uraiantugas dan fungsi dari struktur organisasi.

\section{HASIL DAN PEMBAHASAN}

Alternatif Penyelesaian Masalah

Diperlukan sistem komputerisasi pada pengelolaan data-data dan proses transaksi pada perpustakaan SMP Negeri 01 Citeureup. Penanganan data pencarian buku masih dalam pencatatan manual, sehingga kurangnya keamanan data dan kurang efisien dalam pencarian informasi. Alternatif penyelesaian masalah yang akan peneliti buat adalah dengan membuat program aplikasi sistem informasi perpustakaan secara komputerisasi, untuk mempermudah dalam proses pengolahan data. Program aplikasi ini akan dibuat dengan menggunakan bahasa pemrograman Java Netbeans dan menggunakan database MySQL. Data-data dari proses dan transaksi perpustakaan ini akan disimpan dalam database. Dengan penyimpoanan data pada database ini diharapkan mampu mempermudah dalam proses pencarian data. Pembuatan laporan tahunan juga akan dirasa cukup mudah karena petugas perpustakaan tinggal mencari data yang dibutuhkan dalam file-file yang ada di komputer. Proses perhitungan data-data transaksi yang cukup banuak akan lebih mudah dikerjakan dengan program aplikasi ini. Program aplikasi ini dibuat semudah mungkin dalam proses pengoperasiannya, sehingga petugas perpustakaan tidak begitu kesulitan untuk memahami dan mempelajari proses pengoperasiannya.

\section{Diagram Konteks yang diusulkan}

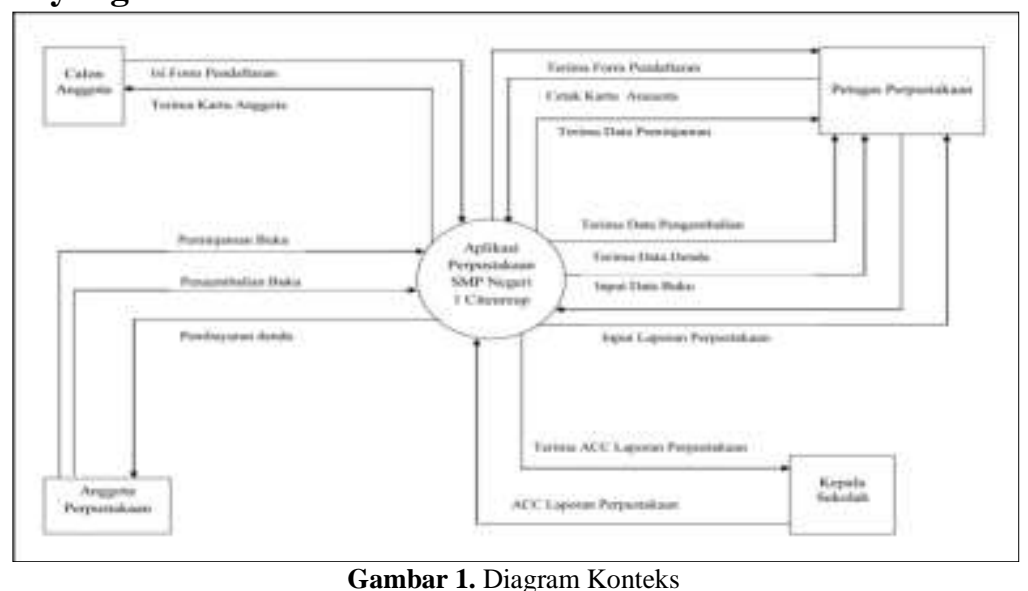

Gambar 1. Diagram Konteks 


\section{Diagram ERD (Entity Relationship Diagram)}

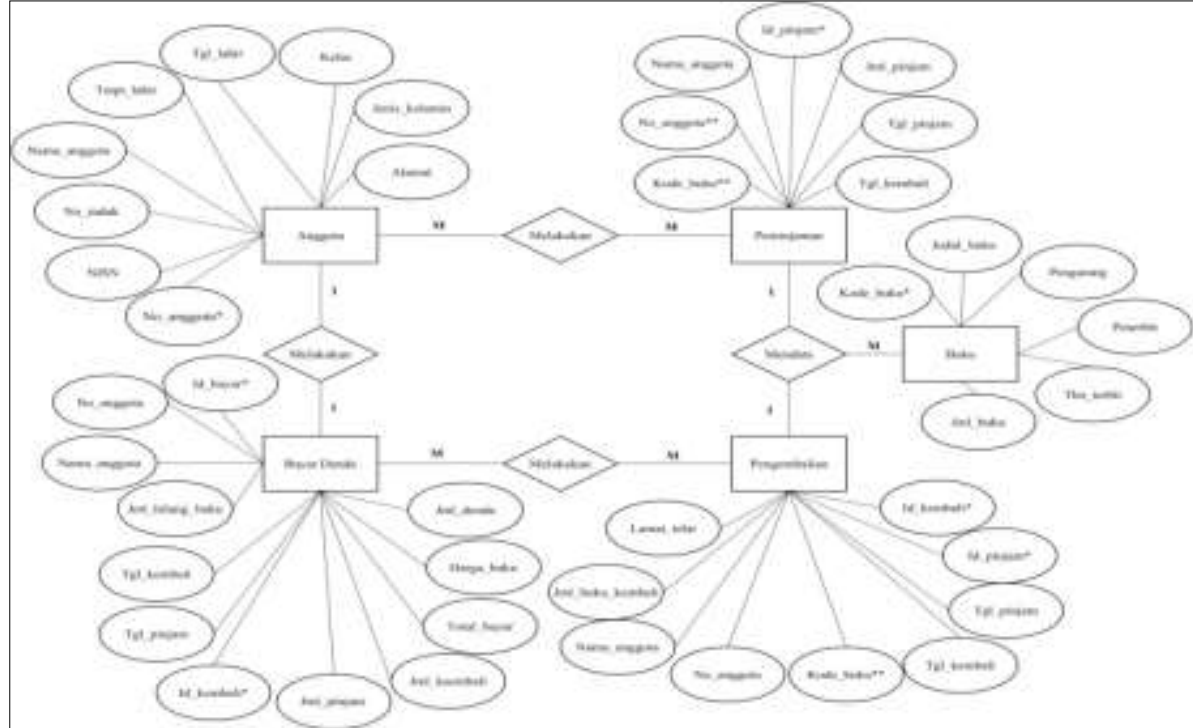

Gambar 2. Entity Relationship Diagram (ERD)

Tampilan Layar, Tampilan Form Masukan, dan Tampilan Keluaran Tampilan Layar

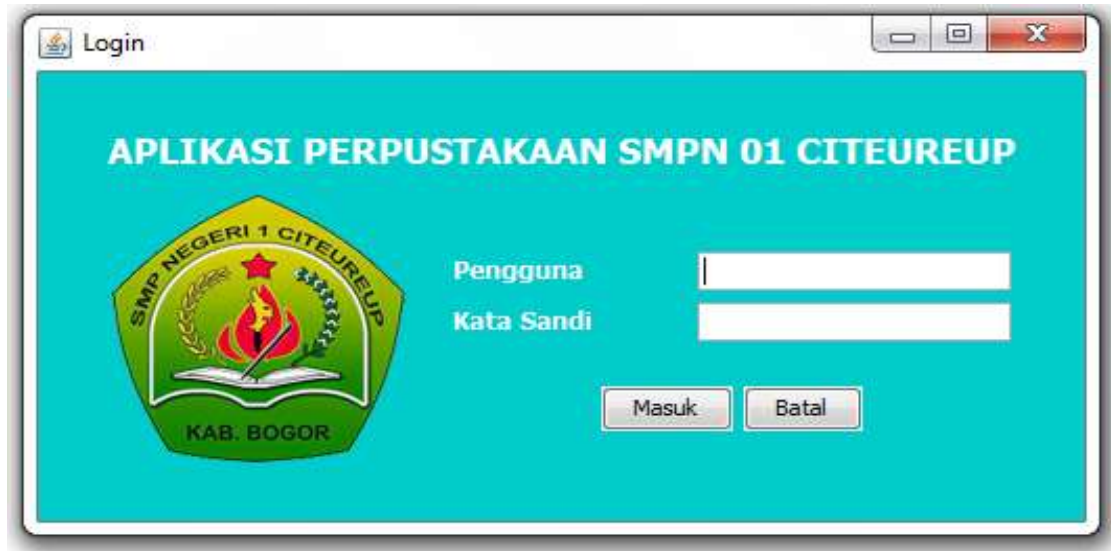

Gambar 3. Menu Login

Tampilan menu login ini muncul di awal saat pengoperasian aplikasi perpustakaan untuk diisi oleh admin sebagai user.

\section{Tampilan Form Masukan}

\section{SMPN 01 CITEUREUP}

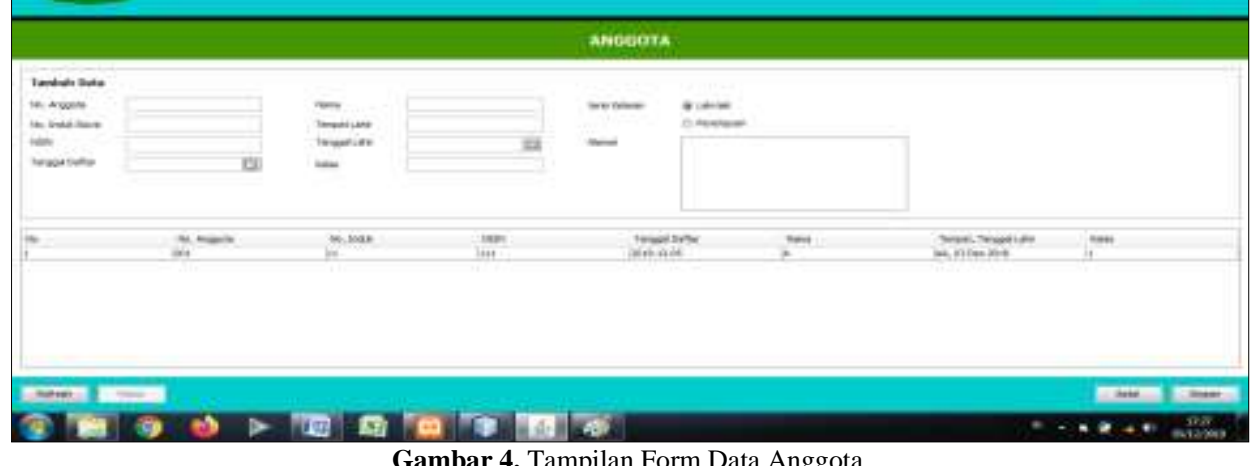

Gambar 4. Tampilan Form Data Anggota 
Tampilan form data anggota ini berfungsi untuk memasukan atau menambah data anggota kedalam basis data.

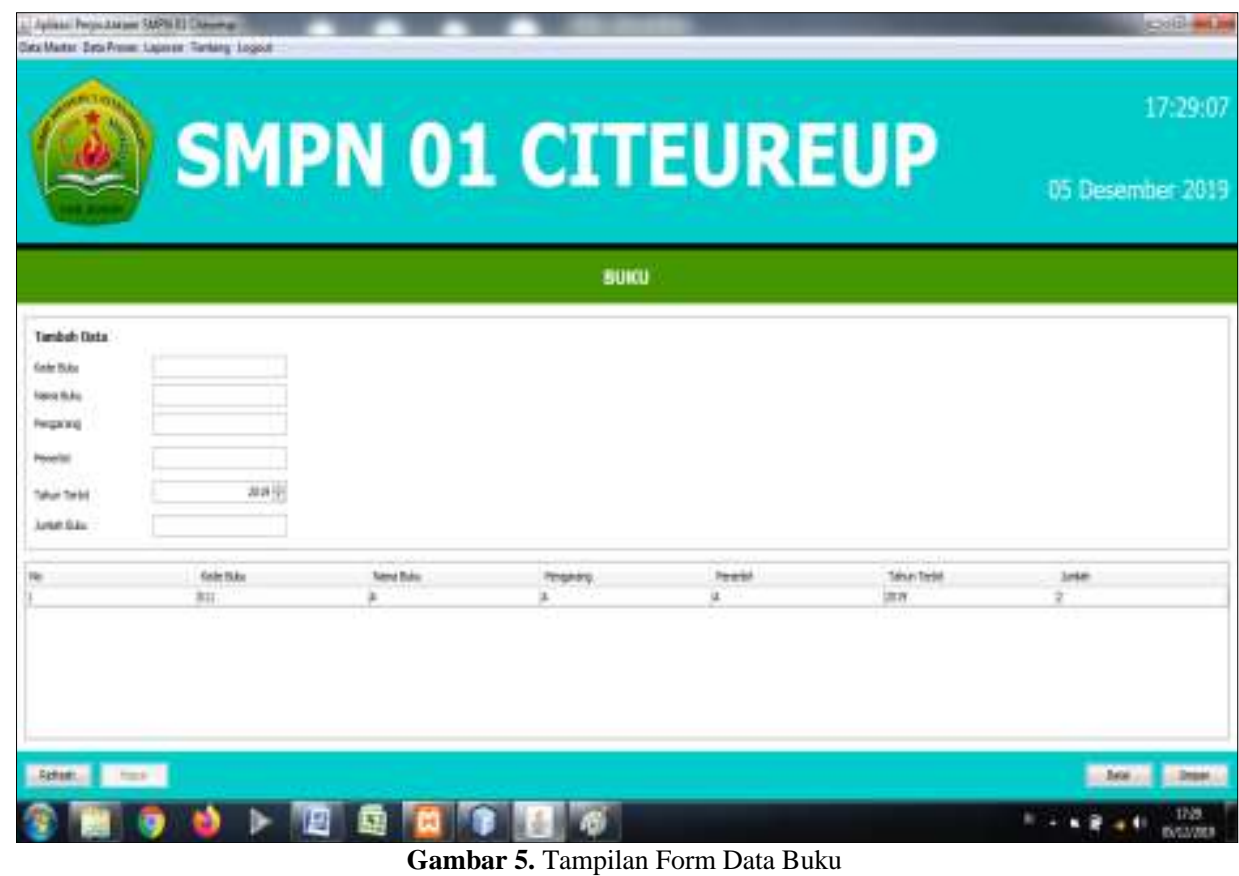

Tampilan form data anggota ini berfungsi untuk memasukan atau menambah data buku kedalam basis data.

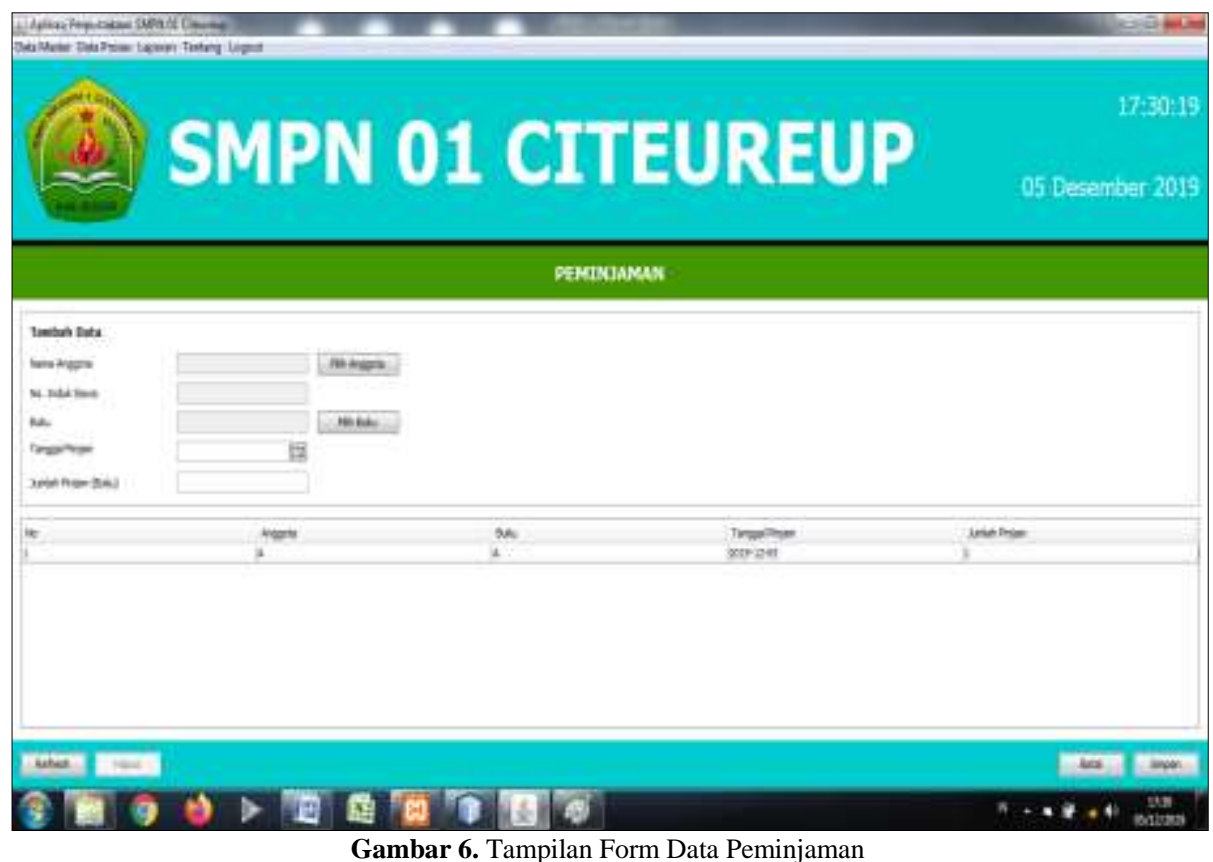

Tampilan form data anggota ini berfungsi untuk memasukan atau menambah data peminjaman kedalam basis data. 


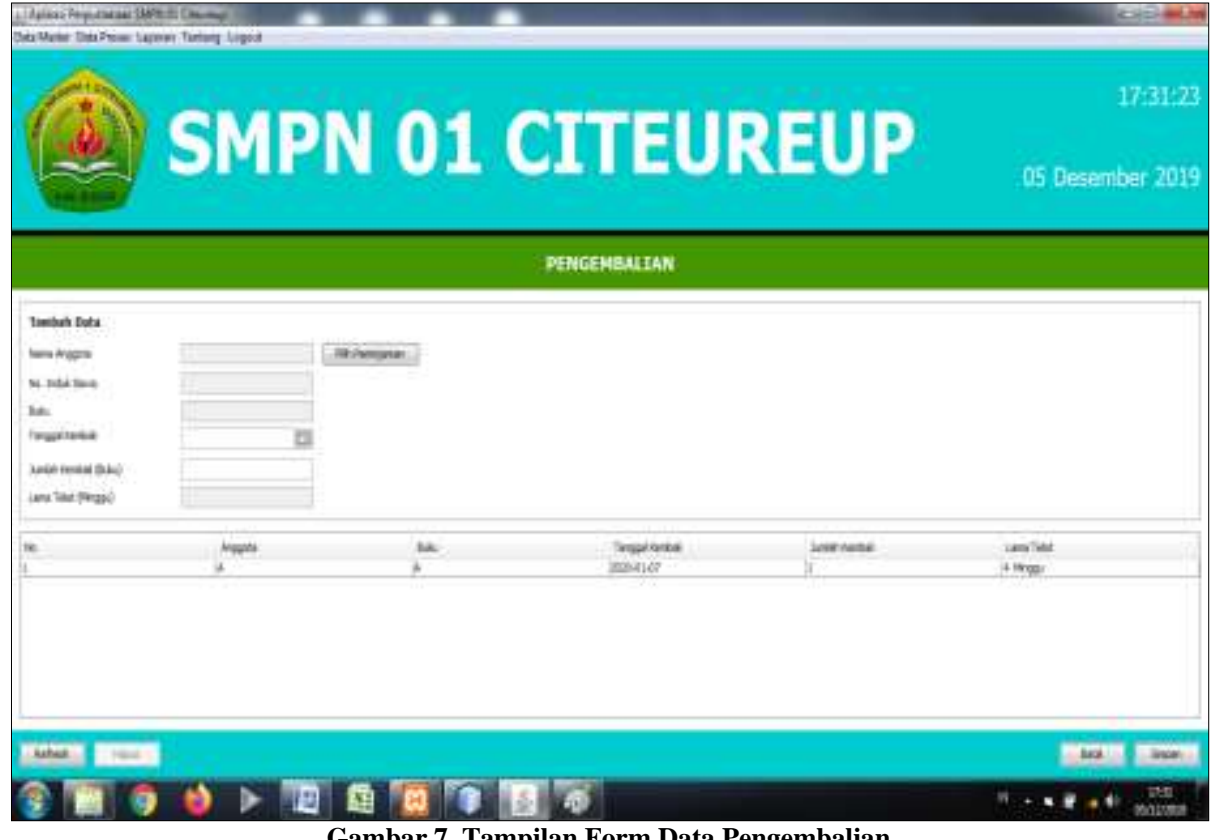

Tampilan form data anggota ini berfungsi untuk memasukan atau menambah data pengembalian kedalam basis data.

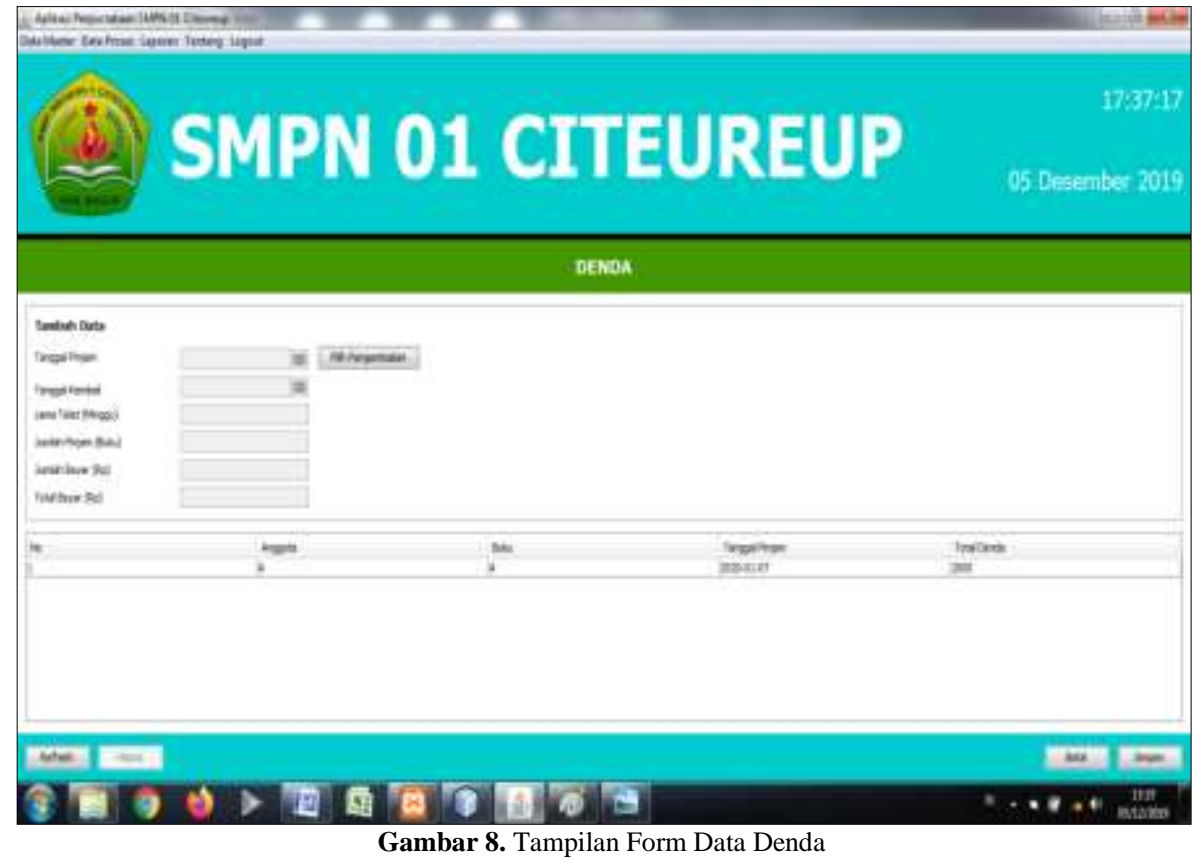

Tampilan form data anggota ini berfungsi untuk memasukan atau menambah data pengembalian kedalam basis data. 


\section{Tampilan Keluaran}

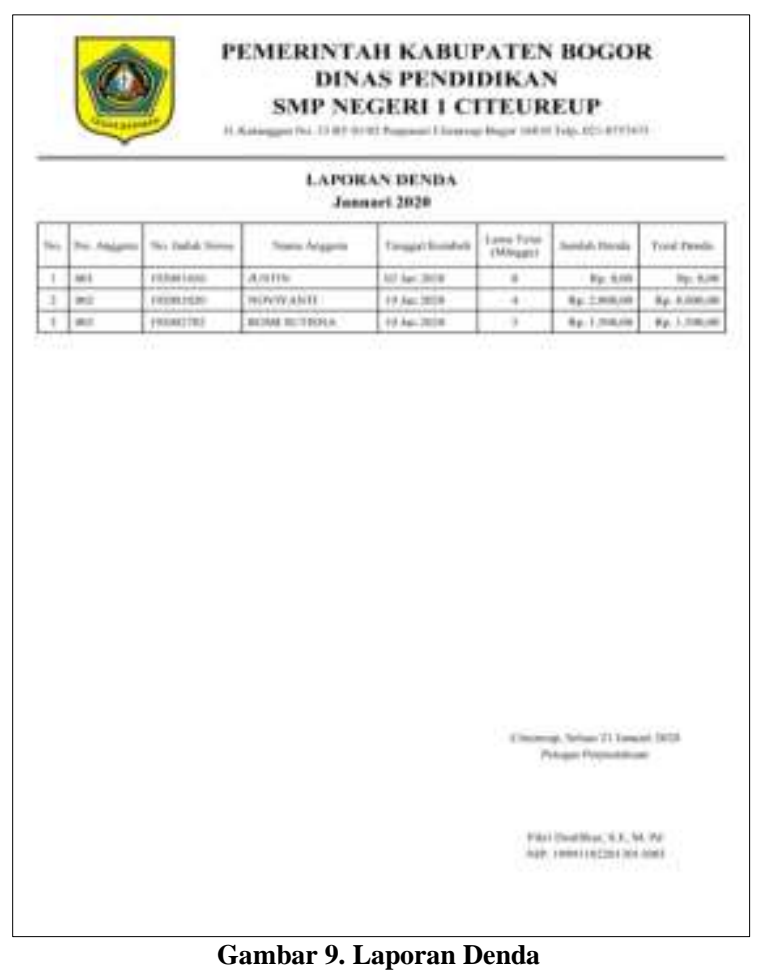

Tampilan keluaran laporan denda berisikan informasi data denda yang akan diberikan kepada kepala perpustakaan setiap bulan dan laporan ini dapat dicetak.

\section{SIMPULAN}

Berdasarkan penelitian dan analisis yang diuraikan di atas maka peneliti dapat menarik simpulan untuk memecahkan masalah yang dihadapi oleh SMP Negeri 01 Citeureup dalam meningkatkan kinerja pelayanan pada perpustakaan yaitu dengan dibuatnya Aplikasi perpustakaan pada SMP Negeri 01 Citeureup yang salah satu terkomputerisasi agar lebih efektif dan efisien, karena tidak perlu lagi melakukan penginputan data secara manual. Aplikasi perpustakaan pada SMP Negeri 01 Citeureup yang dibuat ini memiliki menu login dimana hanya petugas perpustakaan atau admin yang dapat masuk kedalam sistem terserbut, sehingga keamanan data dan kerahasiaan data pada perpustakaan tersebut dapat terjaga dengan baik. Sistem yang terkomputerisasi dapat membantu petugas perpustakaan dalam mengolah data perpustakaan dan mencetak laporan - laporan sehingga kekurangan pada sistem yang lama dapat di minimalisir dan tidak menggunakan buku besar untuk melakukaan pendataan dalam perpustakaan

\section{DAFTAR PUSTAKA}

Bunafit Nugroho. (2014). Database Relasional Dengan MySQL. Andi. Haryanto, B. (2011). Esensi - esensi Bahasa Pemrograman Java. Andi. Jogiyanto. (2012). Analisis dan Desain Sistem Informasi. Andi.

Subtari. (2012). Konsep Sistem Informasi. Andi Offset.

Sutarno, N. (2016). Perpustakaan dan Masyarakat. CV. Sagung Seto.

Suwarno, W. (2010). Pengetahuan Dasar Kepustakaan. Ghalia Indonesia.

Syafriyanto. (2012). Perancangan Sistem Informasi pada Perpustakaan SMK Hidayatut Thalibin Jakarta. Universitas Indraprasta PGRI.

Utapara, F. V. L. (2013). Perancangan Sistem Informasi Perpustakaan Online pada SMP Sint Joseph Jakarta. Universitas Indraprasta PGRI.

Yakub. (2012). Pengantar Sistem Informasi. Graha Ilmu. 